УДК 629.4.028.1

Д-р техн. наук А.М. Муха (ДНУЗТ)

\title{
ДО ПИТАННЯ ВИБОРУ СИСТЕМИ ОХОЛОДЖЕННЯ ТЯГОВИХ ТРАНСФОРМАТОРІВ ПІДВИЩЕНОЇ ЧАСТОТИ
}

Вступ. Питання ресурсозбереження, енергоефективності та енергозбереження в промисловості, на транспорті та інших сферах у сучасних умовах мають велике значення [1,2,3 та ін.]. Одним зі шляхів вирішення цієї комплексної проблеми $\epsilon$ використання електротехнічних систем та пристроїв підвищеної частоти [4,5 та ін.]. Це, як відомо, дозволить підвищити їх питому потужність, тобто зменшиться кількість дефіцитних матеріалів при збереженні тієї самої потужності. Але постає питання про можливість використання розроблених принципів та підходів до проектування існуючих систем забезпечення функціонування електротехнічних пристроїв до нових електротехнічних комплексів підвищеної частоти.

Мета роботи. Провести дослідження питання вибору системи охолодження тягових трансформаторів підвищеної 
частоти, призначених для встановлення на багатосистемних електровозах.

Матеріал і результати досліджень. Більшість тягового рухомого складу, зокрема електровозів, що експлуатуються на залізницях України, були спроектовані ще у 60, 70-ті роки XX ст. та основані на використанні доступних на той час матеріалів і технологій [6,7 та ін.].

До складу сучасних багатосистемних електровозів змінного струму входять однофазні тягові трансформатори, які характеризуються деякими особливостями у порівнянні 3 трансформаторами загальнопромислового виконання [7], а саме: індукція в магнітопроводі (сталь 3404-3405 лист 0,35 мм) не перевищує $1,5 \ldots 1,55$ Тл, що виключає можливість виникнення великих індукцій при підвищенні напруги у контактній мережі (діапазон змін напруги $-10 \ldots+30 \%$ ). Крім того, тягові трансформатори характеризуються мінімальним значенням втрат у сталі, що обумовлено частою роботою трансформатора 3 навантаженням менше номінального.

Втрати у холоднокатаній сталі при підвищеній частоті приблизно визначаються так:

$$
\Delta \partial_{\tilde{n} \check{o}} \sim B^{2}\left(\frac{f}{50}\right),
$$

при базовій індукції 1,0 Тл та базовій частоті 50 Гц [8].

Таким чином, збільшення частоти з 50 до 1000 Гц призведе до приблизного збільшення втрат холостого ходу (при однаковій індукціі) в $\left(\frac{1000}{50}\right)^{1,5}=20^{1,5}=89,4$ разу. Таке збільшення неприпустиме.

Вирішити проблему підвищення робочих частот тягового трансформатора при збереженні або зменшенні втрат неробочого ходу пропонується за рахунок використання сучасних магнітних матеріалів.
Основним показником, який визначає доцільність використання магнітного матеріалу для побудови електромагнітного пристрою, $є$ втрати у магнітопроводі, які складаються із втрат на гістерезис, вихрові струми й втрат внаслідок магнітної в'язкості (або магнітної післядії).

У праці [9] автори на підставі обробки значної кількості статистичних даних щодо втрат у магнітних матеріалах стверджують, що більш раціональним $\epsilon$ метод визначення повних втрат (без поділення на складові) на підставі експериментальних даних, отриманих при синусоїдальному впливі.

Для визначення питомих втрат в стальному магнітопроводі тягового трансформатора підвищеної частоти використаємо таке співвідношення [9]:

$$
p^{`}=\left(\frac{f}{f *}\right)^{\alpha}\left(\frac{B_{m}}{B_{m}^{*}}\right)^{\beta}
$$

де $f$ - частота, Гц;

$B_{m}$ - індукція, Тл;

$f^{*}=1000$ Гц, $\quad B_{m}^{*}=1$ Тл $\quad-$ базові значення частоти та індукції.

Як бачимо в (2), у порівнянні з (1) як базова частота прийнята 1000 Гц.

Позначивши

$$
p_{01}=p_{0}(f *)^{-\alpha}\left(B_{m}^{*}\right)^{-\beta}
$$

отримаємо

$$
p_{01}=p_{0} f^{\alpha} B_{m}^{\beta}
$$

де $p_{0}, \alpha, \beta$ - коефіцієнти, отримані після опрацьовування експериментальних залежностей $p^{\prime}\left(f, B_{m}\right)$ [9].

Враховуючи, що втрати у стальних магнітопроводах при підвищених частотах визначаються втратами на вихрові струми, питому потужність втрат також можна визначити за таким виразом: 


$$
p^{\prime}=A f^{2 / 3} B_{m}^{2}
$$

де $A$ - коефіцієнт, що показує втрати в одиниці об'єму, при частоті 1 Гц та індукції 1 Тл.

Діапазон потужностей, який досліджується для трифазних трансформаторів, слід збільшити також у три рази - від 1000 до 15000 кВт.

Для визначення ефективності використання трифазних трансформаторів підвищеної частоти, у порівнянні 3 трансформаторами промислової частоти, на рисунку подані, відносні до потужності, стандартні значення втрат неробочого ходу трансформаторів, магнітопровід яких зібрано з сталі марок 3404, 3405 або 3406 (товщина стрічки 0,27, 0,3 або 0,35 мм). Дані подані для стандартного ряду потужностей та класів напруг 10 та 35 кВ
[10]. Коефіцієнт потужності приймаємо приблизно $\cos \phi \approx 1$.

Як бачимо з рисунка, використання для виготовлення магнітопроводу трифазного трансформатора підвищеної частоти сталі марки 3424 (0,08 мм) дозволяе зменшити втрати у магнітопроводі приблизно у три рази. Використання сталей інших марок призведе до збільшення втрат у магнітопроводі, у порівнянні 3 трансформаторами промислової частоти, або ці втрати будуть приблизно однаковими (рисунок).

Потужність короткого замикання трифазного трансформатора підвищеної частоти, що розглядається, визначимо зі співвідношення [10]:

$$
P_{0}: P_{\hat{E}}=1:(2,5 \ldots 4) \text {, }
$$

де $P_{0}-$ втрати неробочого ходу.

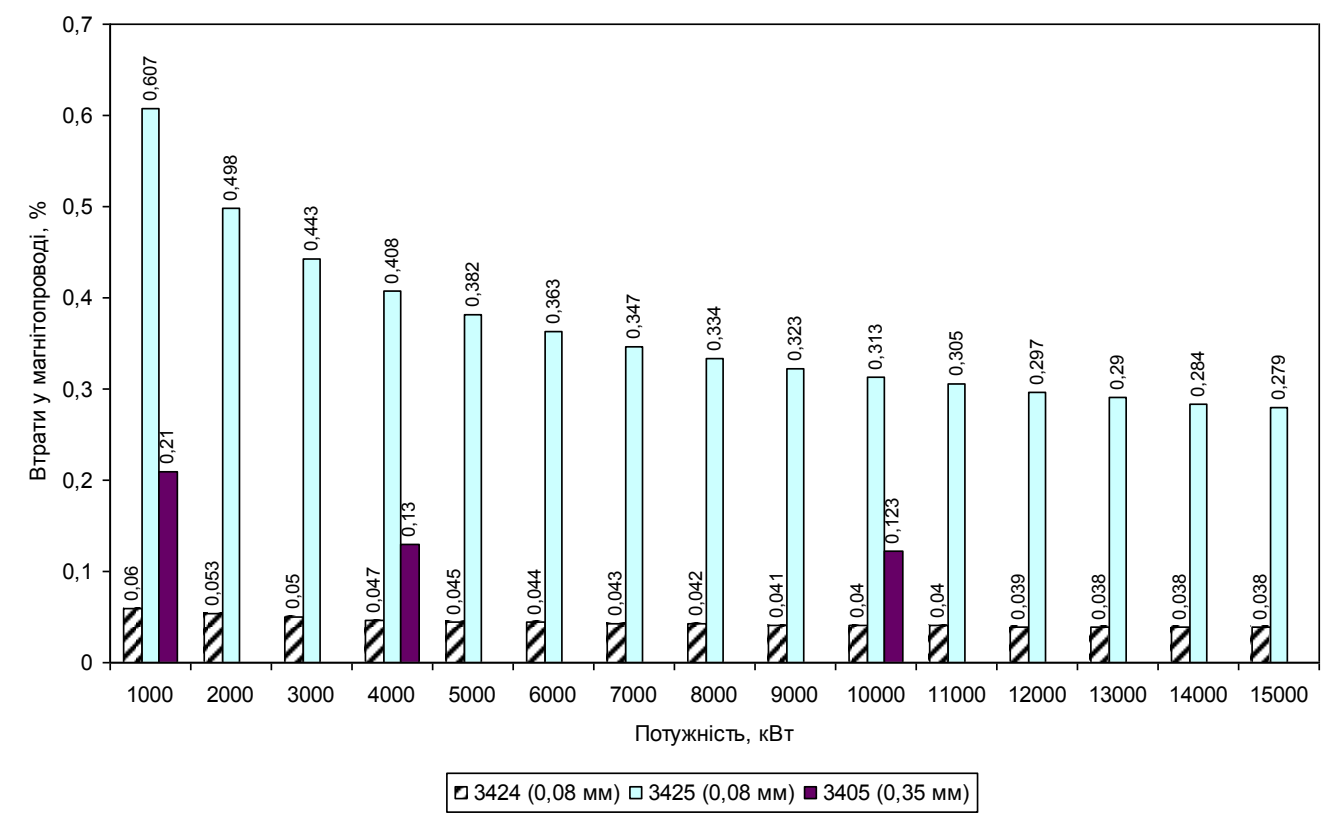

Рис. Відносні втрати у магнітопроводі трифазного трансформатора підвищеної частоти з різних сталей у функції потужності

Приймаючи середнє значення співвідношення втрат неробочого ходу та короткого замикання на рівні трьох,

$$
P_{\hat{E}}=3 P_{0} \text {. }
$$
отримаємо 
Опираючись на отримані раніш значення втрат $P_{0}$, подамо результати розрахунку потужності короткого замикання трансформаторів у таблиці.

Приймаючі інші втрати у трансформаторі на рівні $10 \%$ від сумарних втрат неробочого ходу та короткого замикання, розрахуємо, у першому наближенні, сумарні втрати потужності у трифазному тяговому трансформаторі підвищеної частоти (таблиця).

Традиційно на тяговому рухомому складі використовується примусове рідинне охолодження, яке характеризується мінімальними масогабаритними показниками. Але подані розрахунки показують, що втрати у трифазних трансформаторах підвищеної частоти майже в три рази нижче, ніж в трансформаторах промислової частоти, тому $є$ доцільним провести орієнтовний тепловий розрахунок трансформатора 3 метою обгрунтування вибору його системи охолодження.

Порівняємо між собою дві системи охолодження: масляну примусову та масляну природну.

За критерій попередньої приймаємо значення перепаду температури на поверхні обмотки [10].

Таблиця

Втрати короткого замикання трифазних трансформаторів підвищеної частоти

\begin{tabular}{|l|c|c|c|c|c|}
\hline \multirow{2}{*}{ Параметр } & \multicolumn{5}{c|}{ Потужність, кВт } \\
\cline { 2 - 7 } & 1000 & 1600 & 2500 & 4000 & 6300 \\
\hline Втрати неробочого ходу $P_{0}$, Вт & 602 & 887 & 1283 & 1890 & 2750 \\
\hline Втрати короткого замикання $P_{\hat{\mathrm{e}}}, \mathrm{B}$ т & 1806 & 2661 & 3849 & 5670 & 8250 \\
\hline Приблизні сумарні втрати, Вт & 2649 & 3903 & 5645 & 8316 & 12100 \\
\hline
\end{tabular}

Перепад температури на поверхні обмотки визначається так [10]:

$$
\Theta_{\check{I} \hat{I}}=k_{1} k_{2} k_{3} \cdot 0,35 q^{0,6}
$$

де $k_{1}$ - коефіцієнт, який враховує швидкість руху охолоджуючої рідини $(1,0$ - для рідинного охолоджування без циркуляції та 0,7 - для примусового охолодження);

$k_{2}$ та $k_{3}-$ коефіціснти, які враховують конструктивні особливості, приймаємо їх на рівні 1,0 .

Головним показником у (8) $є$ щільність теплового потоку на поверхні обмоток $q$, яка визначається так:

$$
q=\frac{P_{\mathrm{K}}}{\ddot{I}_{\hat{\mathrm{I}}}},
$$

де $\ddot{I}_{\hat{\mathrm{I}}}-$ площа поверхні охолодження обмоток.

Орієнтовне значення щільності теплового потоку на поверхні мідних обмоток трансформатора промислової частоти дорівнює 1400 Âò $/$. $^{2}$. Тоді при зменшені втрат в обмотці приблизно у три рази це значення також зменшиться у три рази до значення $\frac{1400}{3}=467$ Âò $/{ }_{2}$. Але це не враховує той факт, що зі збільшенням частоти зменшуються габаритні розміри $\mathrm{i}$ обмоток трансформатора, тобто зменшується площа поверхні охолодження обмоток $\ddot{I}_{\hat{I}}$. Попередні дослідження автора [11] показали, що об'єм трансформатора також зменшується приблизно у три рази. Тоді, виходячи 3 того, що обмотка має форму циліндра, іiі 


\section{Організація перевезень і управління на транспорті}

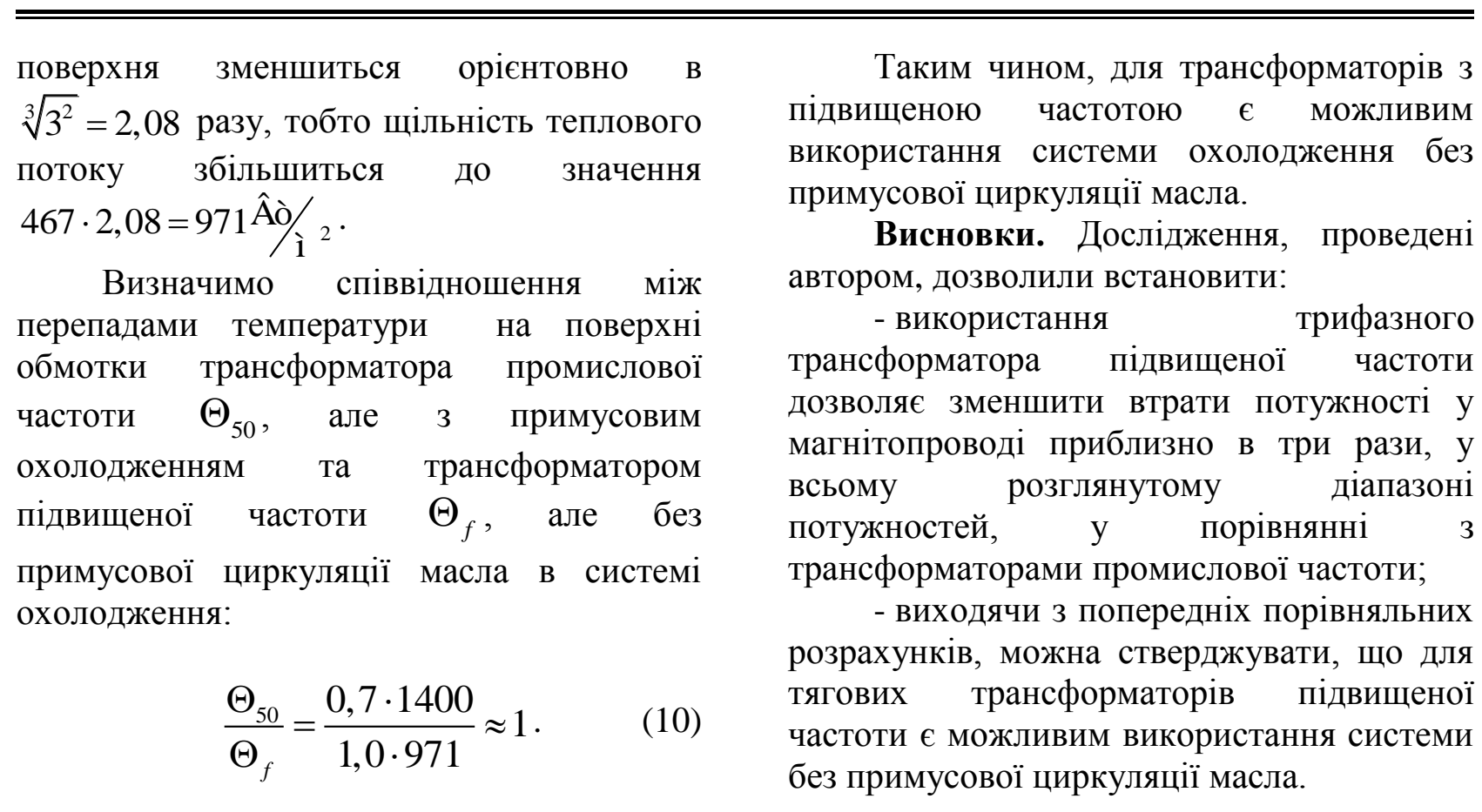

\section{Список літератури}

1. Лашко, А.Д. Енергозбереження на залізничному транспорті України [Текст] / А.Д. Лашко // Залізничний транспорт України. - 2001. - №4. - С. 7-11.

2. Дудка, Н.В. Напрямки розвитку локомотивного господарства України [Текст] / Н.В. Дудка // Залізничний транспорт України. - 2001. - №4. - С. 16-18.

3. Лашко, А.Д. Технічні вимоги до тягового рухомого складу нового покоління [Текст] / А.Д. Лашко, С.Г. Грищенко // Залізничний транспорт України. - 2008. - №3. - С. 11-14.

4. Муха, А.М. Підвищення робочих частот - перспективний шлях удосконалення тягового обладнання електровозів подвійного живлення [Текст] / А.М. Муха, Л.В. Дубинець, Г.М. Чілікін // Проблеми та перспективи розвитку залізничного транспорту: міжнар. наук. практ. конф., 24-25 травня 2007 р.: тези доп. - Дніпропетровськ: ДНУЗТ, 2007. - С. 107-108.

5. Steimel A. Power-Electronics Issues of Modern Electric Railway Systems / A. Steimel // Advances in Electrical and Computer Engineering. vol. 10. - №2. - 2010. - P.3-10.

6. Проектирование и изготовление электрооборудования для электрической тяги. Руководящие технические материалы [Текст]. - М.: ВНИИЭМ, 1968. - 276 с.

7. Захарченко, Д.Д. Подвижной состав электрических железных дорог. Тяговые электрические машины и трансформаторы [Текст] / Н.А. Ротанов, Е.В. Горчаков, П.Н. Шляхто. М.: Транспорт, 1968. - 296 с.

8. Безрученко, В.Н. Электрические машины [Текст] / В.Н. Безрученко, А.С. Хотян. К.: Вища школа, 1987. - 215 с.

9. Горский, А.Н. Расчет электромагнитных элементов вторичного электропитания [Текст] / А.Н. Горский, Ю.С. Русин, Н.Р. Иванов, Л.А. Сергеева. - М.: Радио и связь, 1988. $176 \mathrm{c}$.

10. Тихомиров, П.М. Расчет трансформаторов [Текст] / П.М. Тихомиров. - М.: Энергоатомиздат, 1986. - 528 с.

11. Муха, А.М. До питання вибору матеріалів магнітопроводу тягового трансформатора підвищеної частоти [Текст] / А.М. Муха, Р.В. Краснов, О.О. Карзова // Електромеханічні і енергозберігаючі системи. - 2013. - №1/2013 (21). - С. 107-115. 
Ключові слова: частота, втрати, трансформатор, охолодження.

\section{Анотації}

Подано порівняльний аналіз потужності втрат у тяговому трансформаторі промислової та підвищеної частоти з метою вибору його системи охолодження.

Представлен сравнительный анализ мощности потерь в тяговом трансформаторе промышленной и повышенной частоты с целью выбора его системы охлаждения.

The Presented benchmark analysis to powers of the losses in traction transformer industrial and raised frequencies for the reason choice of its system of the cooling. 